\title{
The Usage of Emergency Contraceptive Methods of Female Students in Hawassa University: A Case Study on Natural and Computational Science
}

\author{
Gezahegn Mekonnen, Nebro Wendmagegn, Demisew Gebiru \\ School of Mathematical and Statistical Sciences, Hawassa University, Hawassa, Ethiopia \\ Email address: \\ gm775043@gmail.com (G. Mekonnen),nebrowend1@gmail.com (N. Wendmagegn), gebrudemisew2016@gmail.com (D. Gebru) \\ To cite this article: \\ Gezahegn Mekonnen, Nebro Wendmagegn, Demisew Gebiru. The Usage of Emergency Contraceptive Methods of Female Students in \\ Hawassa University: A Case Study on Natural and Computational Science. American Journal of Theoretical and Applied Statistics. \\ Vol. 6, No. 1, 2017, pp. 61-71. doi: 10.11648/j.ajtas.20170601.18
}

Received: December 17, 2016; Accepted: January 3, 2017; Published: February 24, 2017

\begin{abstract}
Students in the higher education are found in adolescent period. Because of this, they are exposed to unwanted pregnancy that leads them to attempt illegal abortion, which results in death or illness or loss of future fertility and on the other hand, they are obliged to leave their education. The objective of the study is to assess the factors that affect female studentsemergency contraceptive usagein HU in case of Colleges of Natural and Computational Sciences. The significance of the study is to create some insight on the female students about contraceptive methods and to save female students from illegal abortion, unwanted pregnancy and other related problems. The source of data is primary data and it was collected using questionnaires. The statistical model under consideration was logistic regression and chi-square test of association. In descriptive part, the majority of student $(77.6 \%)$ isless than 22 years old and $42.4 \%$ are third year students. Sixty percent of the respondents come from urban area and the parental educational level of $36.8 \%$ of the respondents is higher education level. Most of the female students accessedinformation of emergency contraceptive from health professional, media and from their friends. $51.2 \%$ of Natural and Computational Sciences female students are familiar with ECM, but the rest $48.8 \%$ of female students not use emergency contraceptive at all. The usage of emergency contraceptive method are associated with where the female students heard and get the ECM, their marital status, parent's educational level and batch of students. The female students usage of ECM affected by source and information about emergency contraceptive method (ECM), their marital status and batch of students. Hence HU should prepare panel discussion, post some poster which talk about ECM in some areas like in clinic, invite some guests from the family planning bureau to teach the students when and how to use the ECM.
\end{abstract}

Keywords: Emergency Contraceptive, Higher Education, Logistic Regression

\section{Introduction}

Emergency contraception is contraception administered after unprotected sexual intercourse. Emergency contraception (EC) is the only method women can use to prevent pregnancy after they have unprotected sexual intercourse, have experienced a contraceptive failure, have remember too late that they have forgotten to take their birth control pills and have been forced to have sex against their well. Emergency contraception is sometimes referred to as "morning after" or "post-coital" contraception. Emergency contraception (EC) is intended for occasional or emergency use only and not as a regular means of contraception.
Formerly, EC was thought to be effective only with 72 hours, but recent studies have confirmed it is effective for up to 120 hours. Emergency contraception method includes taking special doses of ordinary birth control pills as well as inserting an intrauterine device (IUD).

Emergency contraceptive pills (ECPs) are oral contraceptive pills that women can take within 72 hours after unprotected intercourse to reduce her risk of becoming pregnant. The resent research suggested the pills are effective if taken within 120 hours of unprotected intercourse. They intended for use after sexual intercourse when no contraception methods used, when a regular contraceptive method does not use properly a daily oral contraceptive 
method missed. There are two types of ECPs have been rigorously studied during the past of 30 years. The more effective regimen is a progestin only pill. Several manufactures now package and brand an effective dosage as a dedicated emergency contraceptive pills product [22]

The pills sometimes cause nausea headache cramping breast tenders the pills also may cause irregular bleeding until woman menstruated again and menstruated may begin early or later.

In the world health organization study cited previously about $20 \%$ at women taking the combined Emergency contraceptive pills experienced to vomiting and $50 \%$ hand nausea compared to only $6 \%$ with vomiting and $20 \%$ with nausea among those taking the progestin only pill. The awareness of emergency contraceptive method of pill is increased but access to it still be problematic for adolescents.

In a study of women having abortions in 2000-2001, only $46 \%$ reported that they had not used any form of contraception during the month in which they conceived [11]. Further, inconsistent use of contraception (49\% of condom users and $76 \%$ of birth-control pill users) was the most commonly cited reason for method failure. Many women reported not using contraception because they did not feel that they were at high risk of pregnancy, and $32 \%$ failed to use contraception because they were concerned about potential side effects. The women who reported condom use as their primary method of birth control, condom breakage or slippage was cited as the reason for unintended pregnancy [11].

The demographic and health survey from 2000 show that fewer than $2 \%$ of youth ages 15 to 24 have ever used emergency contraceptive method in America, Cambodia, Malawi, Turkey and Uganda. In survey sexually active youth in 2000 to 2001,10 percent of Jamaican university female students had used emergency contraceptive pills.

Emergency contraception adds an important option for helping sexually active adolescents avoid unintended pregnancy. Many adolescent females are at high risk of unintended pregnancy. They have limited knowledge of contraception and generally lack access to services or do not feel comfortable using these services. According to the Demographic and Health Surveys (DHS) in Ghana, Kenya, Namibia, and Nigeria, the proportion of currently pregnant women under age 20 who reported that their pregnancies were mistimed or unwanted was 46 percent, 50 percent, 55 percent, and 58 percent, respectively. The steadily decreasing age of menarche and increasing age of marriage have created a widening window of time for premarital sexual intercourse and pregnancies. Even in countries where age at first intercourse has risen, the increase in age of marriage is usually greater, resulting in a widening gap. [2]. Studies have found a delay of about one year on average between starting sexual activities and first use of modern contraceptives. Many unplanned pregnancies occur within a year after first sexual intercourse

Depending on the method used, Emergency contraception (EC) can reduce women's risk of becoming pregnant from a single act of intercourse by between 75 and 99 percent. Reasons for such huge number of unintended pregnancies include a low rate of contraceptive used, method failure, and high unmet need for contraceptive. Each year about 210 million women around the world become pregnant among them, about 75 million pregnancies $36 \%$ are unplanned or unwanted pregnancy is one the leading cause of maternal mortality and morbidity. Each year worldwide, more than 20 million women experience ill health because of pregnancy. It is estimated that between 8 and 30 million pregnancies each year result from contraceptive failure either due to inconsistent or incorrect use of contraceptive methods. Research studies conducted in the USA have reported that higher rates of unintended pregnancy occur among collegeage women, with $60 \%$ of pregnancies among 20-24 years old being unintended. The $79 \%$ of unintended pregnancy is even higher among 18-19-year-old females [14].

In Nepal, the data suggest that more than a third (35\%) of all pregnancies and $41 \%$ of the current pregnancy among currently pregnant women are unintended. The prevalence of premarital sex has been reported as 39\% among college males and $12 \%$ among college females. A considerable proportion of both males $(10 \%)$ and females $(22 \%)$ reported that their first sexual intercourse happened without their consent. These students are at the greatest risk of unintended pregnancy. A study has also found that a large proportion of college students who were studying in Kathmandu (43\% of males and $55 \%$ of females) did not use a condom during their first sexual intercourse [16].

In developing country, WHO estimates that one woman dies every eight minutes due to unsafe abortion. In Africa, such as Gahanna, Emergency contraceptive pills have now become an integral part of contraceptive services to prevent conception following unprotected and unplanned exposure or contraceptive accidents like slippage of diaphragm and forgotten pills. Also Emergency contraceptive pills are used by victims of rape cases. There has been very extensive campaign and dissemination of knowledge of any contraceptive method is almost universal in Gahanna, with $98 \%$ of all women and $99 \%$ of all men knowing at least one method of contraception. However, $47.4 \%$ of Gahanna women have a history of contraceptive use only $20 \%$ are current user [17].

In case of our country Ethiopia, reproductive health need assessment report showed that there is little knowledge and information available about emergency contraceptive. Unwanted pregnancy is one of the most commonly observed reproductive health problems in Ethiopia. The [23] reported that $35 \%$ pregnancies among women in reproductive age were unintended. The major factor limiting the use of Emergency contraception was inadequate information about their effectiveness and availability or unfavorable opinions about their safety due to misinformation. The limited studies conducted on the issue of Emergency contraception in the country, most of them focused on university students. Since most of college students are from rural areas, where the chance of getting information on sexual and reproductive 
health is limited and most go outside campus and without parents' supervision, their vulnerability to unintended sex and unwanted pregnancy is high [3]. In case of south Ethiopia, in Hawassa University, female students had been experiencing high rate of unintended sexual practice and pregnancy. The resent study shows that $41.9 \%$ of female students ever had sexual intercourse and from this, $2.2 \%$ are experienced forced sex. Oral contraceptive pills were the most widely used form of all emergency contraceptive [6].

Statement of the Problem

The proportion of adolescents in the population is increasing and so the extent of their involvement in sexual activity. Students of the higher education are found in adolescent period. Because of this, they are able to have unwanted pregnancy that leads them to attempt illegal abortion, which results in death or illness or loss of future fertility, and on the other hand, they are obliged to leave their education. Therefore, one can need to have meant on how to prevent pregnancy by way of contraception, to save the life of these people and increase the socio-economic development of the country. Since contraception provide as safe and effective way to regulate fertility and improves women's healthy by preventing unwanted and high-risk pregnancies and reducing the need for unsafe abortion [13]

The study was attempts to addresses the following research questions:

1. What are the major barriers in using ECM?

2. Are most of the students of the university having awareness about usage of ECM?

3. Where the students get information about ECM?

Objective of the Study

The general objective of this study would be to assess the usage of emergency contraceptive method of female students in Hawassa University in case of Natural and Computational Science.

Specific Objective

1. To see the major factors that affect female students on the usage of emergency contraceptive method.

2. To identify the preference sources of information to female students among emergency contraceptive method.

3. To see where the female students get information about the usage of emergency contraceptive method.

4. To recommend the concerned body based on the result and discussion part.

\section{Methodology}

\subsection{Description of Study Area}

The study was conducted in Hawassa University. Hawassa University is established in 1976 and it is located in historic city of SNNPR, Hawassa, Ethiopia. It was almost 273 kilometers far from Addis Ababa and one of the bigUniversities in Ethiopia. Hawassa University formerly called Debub University and with the amalgamation of four independently operating Colleges Hawassa College of
Agricultural, Wondogenet College of Forestry and Natural Resource, Dilla College of Teacher Education and Health. Currently Hawassa University has six Branch Campuses. This study was conduct on main campus in case of Natural and Computational Sciences. It consists six different departments, Mathematics, Statistics, Physics, Biology, Chemistry and Sport Science.

\subsection{Study Design}

In this study, the cross-sectional study design was used. The data were obtained through self-administered questionnaire. The questionnaire was designed to capture both qualitative and quantitative information related ECM.

\subsection{Sampling Design and Technique}

The sampling technique used in this study was stratified random sampling technique where the population is divided in to strata that represent clearly defined groups of units within the population.

\subsection{Sample Size Determination}

The question of how large a sample to take arises early in the planning of any survey. This is an important question that should not be treated lightly. To take a representative sample which is needed to achieve the desired results. The appropriate sample size used for this study was obtained using the following formula [5].

$$
\mathrm{n}=\frac{\sum_{h=1}^{2}\left(W_{h}^{2} S_{h}^{2} / W_{h}\right)}{V+\frac{\sum_{h=1}^{2} W_{h} S_{h}^{2}}{N}}
$$

where $V=\left(\frac{d}{\mathrm{Z}_{\alpha / 2}}\right)^{2}$, is the specified variance of the estimate and in case of estimating proportion, the stratum variance is given by $S_{h}{ }^{2}=\frac{N_{h}}{N_{h}-1} P_{h} Q_{h}=S_{h}{ }^{2}=\frac{N_{h}}{N_{h}-1} P Q$ for common $p$. Since we use proportional allocation sample, $w_{h}=n_{h} / n=$ $N_{h} / N, w_{h}$ stands for stratum weight, $\mathrm{N}=\mathrm{N}_{1}+\mathrm{N}_{2} \mathrm{~N}_{3}$.

For this study, $\mathrm{p}=0.5$ is used. This choice is determined from the previous study. The sampling error is also called the level of precision in sampling contexts. In this study a value of sampling error of 4 percent at 5 percent significance level will used referring to similar studies.

$$
n=\frac{\sum_{h=1}^{2}\left(W_{h}{ }^{2} N_{h} P Q / W_{h}\left(N_{h}-1\right)\right)}{V+\frac{\sum_{h=1}^{2}\left(\frac{W_{h} h_{h} P Q}{N_{h}-1}\right)}{N}}=\frac{0.12054}{0.00097}=124.26804=125
$$

Thus, the required sample size for this study was 125 students from 788who were belongs to College of Natural and Computational Science, Hawassa University, Next, the researcher carried out sample size allocation to each stratum with proportional allocation. Proportional allocation of total sample size to each batch is performed. 
The population of $\mathrm{N}$ units was first divided in to sub populations of N1, N2, and N3 units respectively. Therefore, There were three stratums, namely stratum one for $1^{\text {st }}$ year students, stratum two for $2^{\text {nd }}$ year students and stratum three for $3^{\text {rd }}$ year students.

Table 1. Proportional allocation of total sample size to each butch (HU,2016).

\begin{tabular}{lllll}
\hline S. $\mathbf{N}$ & Stratum & Total number of studentsin each butch $\mathbf{~ i}$ & $\mathbf{( N i / \mathbf { N } )}$ & Proportional Allocation to each Bach ni=n((Ni/N) \\
\hline 1 & Year one & 523 & 0.663706 & 82.9632 \\
2 & Year two & 106 & 0.134518 & 16.81472 \\
3 & Year three & 159 & 0.201777 & 25.22208 \\
4 & Total & 788 & 1 & 125 \\
\hline
\end{tabular}

\subsection{Variables of the Study}

Dependent variable: practice of emergency contraceptive method (contraceptive practice status of female students, by classifying as non-user and user coding as 0 and 1 respectively).

Independent Variables

Table 2. Independent variables with their categories (HU, 2016).

\begin{tabular}{|c|c|c|c|c|c|}
\hline Variables & Category & Code & Variables & Category & Code \\
\hline & Less than 22 & 0 & 6) Parent & less than 500 & 0 \\
\hline \multirow[t]{2}{*}{ 1) Age } & $22-25$ & 1 & monthly & $500-1000$ & 1 \\
\hline & More than 25 & 2 & income & $1001-1500$ & 2 \\
\hline 2) Religion & Orthodox & 0 & & More than 1500 & 3 \\
\hline \multirow[t]{3}{*}{ of students } & Protestant & 1 & 7) Net & Less than 150 & 0 \\
\hline & Muslim & 2 & monthly & $150-300$ & 1 \\
\hline & Catholic & 3 & income & $300-500$ & 2 \\
\hline 3) Batch of & one year & 0 & 8) Educational & Illiterate & 0 \\
\hline \multirow[t]{3}{*}{ Students } & Two year & 1 & Level of & Primary & 1 \\
\hline & Three year & 2 & Parent & High school & 2 \\
\hline & $>$ three year & 3 & & high school \& above & 3 \\
\hline 4) Marital & Single & 0 & 9) Reason & I didn’t know use & 0 \\
\hline status of & Married & 1 & why not use & I couldn't get easily & 1 \\
\hline Students & Divorced & 2 & ECM & Not allowed in & 2 \\
\hline \multirow{2}{*}{ 5) Residence } & & & 10) Source \& & Teacher & 0 \\
\hline & & & information & Media & 1 \\
\hline \multirow[t]{3}{*}{ of Student } & Urban & 1 & ofECM & Health profession & 2 \\
\hline & & & & Parent & 3 \\
\hline & & & & Friends & 4 \\
\hline
\end{tabular}

\subsection{Method of Data Analysis}

In this study, both descriptive statistics and inferential statistics were used to analyze the given data.

\subsubsection{Logistic Regression Model}

Logistic regression analysis extends the techniques of multiple regression analysis to research situations in which the outcome variable is categorical. Logistic regression allows to predict a discrete outcome, such as group membership, from a set of predictor variables may be continuous, discrete, dichotomous, or mixed [7].

Generally, the response variable is binary, such as emergencycontraceptive practice status of a students, by classifying as non-user and user coding as 0 and 1 respectively. The logistic regression is also preferred to multiple regressions and discriminated analysis as it results in a biologically meaningful interpretation, it is mathematically flexible and easily used distribution and it requires fewer assumptions [12]. In the context of this study the dependent variable was emergency contraceptive usage status of students, by classifying as non-user and user coding as 0 and 1 respectively.

There are two main uses of logistic regression: Firstly, to predict the group membership. Since logistic regression calculates the probability of success over the probability of failure, the results of the analysis are in the form of an odds ratio. Secondly, logistic regression also provides knowledge of the relationships and strengths among the variables.

\subsubsection{Model Description}

Since the response variable in logistic regression is usually dichotomous, we were define such a response variable as $\mathrm{Y}$, and denote the even $\mathrm{y}=1$, when the subject has the characteristic of interest and $\mathrm{y}=0$, when the subject does not have that characteristic of interest. In logistic regression, a single outcome variable $Y_{i}(i=1 \ldots n)$ follows a Bernoulli probability function that takes the value 1 with probability of success $p_{i}$ or the value 0 with probability of failure $1-p_{i}$. This type of variable is called a Bernoulli variable. The predictor variables in logistic regression could be discrete, continuous or mix of both. 
In logistic regression, the relationship between the predictor and response variable is not linear. Instead, the logistic regression function is used, which is the logit transformation of parameter and we assume that $\mathrm{Y}$ is dichotomous, taking on values of 1 (success) and 0 (failure).

Logistic regression model were used in order to address the issues under objectives of this study. And in this case, In the context of this study the dependent variable was contraceptive practice status that represent $Y_{i}=1$, when female students not use emergency contraceptive method and $Y_{i}=0$, when they are use emergency contraceptive method.

The logistic model is defined $Y_{n \times 1}$ be a dichotomous outcome random variable with categories 0 and 1 code. Let $\mathrm{X}_{(\mathrm{n} \times(\mathrm{k}+1))}$ denote the point in $(\mathrm{k}+1)$ dimension space variables of $\mathrm{Y}$, where

$$
\mathbf{X}=\left(\begin{array}{rrrrl}
1 & X_{11} & X_{12} & \cdots & X_{1 k} \\
1 & X_{21} & X_{22} & \cdots & X_{2 k} \\
\cdot & \cdot & \cdot & \cdots & \cdot \\
\cdot & \cdot & \cdot & \cdots & \cdot \\
1 & \cdot & \cdot & \cdots & \cdot \\
1 & X_{n 1} & X_{n 2} & \cdots & X_{n k}
\end{array}\right)
$$

$\mathbf{X}$ is called regression matrix and without the loading column of $1 \mathrm{~s}$ is termed as predictor data matrix. Then, the conditional probability that an employee is use contraceptive method given that $\mathbf{X}$ set of predictor variable is denoted by $\mathrm{P}\left(\mathrm{Y}_{\mathrm{i}}=1 / \mathrm{X}_{\mathrm{i}}=\mathrm{P}_{\mathrm{i}}\right)$. The expression $\mathrm{P}_{\mathrm{i}}$ in logistic regression model can be expressed in the form of:

$$
\mathrm{P}_{\mathrm{i}}=\frac{e^{\left(\beta_{0}+\beta_{1} X_{i 1}+\cdots+\beta_{k} X_{i k}\right)}}{1+e^{\left(\beta_{0}+\beta_{1} X_{i 1}+\cdots+\beta_{k} X_{i k}\right)}}=\frac{e^{X \beta}}{1+e^{X \beta}}
$$

Where $\mathrm{P}\left(\mathrm{x}_{\mathrm{i}}\right)$ is the probability of $\mathrm{i}$ students can't use contraceptive, for $\mathrm{x}$ predictors.

And, $1-\mathrm{P}\left(\mathrm{x}_{\mathrm{i}}\right)$ is the probability of $\mathrm{i}^{\text {th }}$ student being use contraceptive, for $\mathrm{x}$ predictors.

$\beta \sim(\mathrm{k}+1) \mathrm{x} 1$ is a vector of unknown coefficients.

However, the relationship between the predictor and response variables is not a linear function in logistic regression; instead, the logarithmic transformation of equation yields the linear relationship between the predictor and response variables. So an alternative form of the logistic regression equation is the logit transformation of $\mathrm{P}_{\mathrm{i}}$ given as

$\operatorname{logit}\left[P_{i}\right]=\log \left(\frac{P_{i}}{1-P_{i}}\right)=\beta_{0}+\beta_{1} \mathrm{X}_{\mathrm{i} 1}+\beta_{2} \mathrm{X}_{\mathrm{i} 2}+\cdots+\beta_{\mathrm{k}} \mathrm{X}_{\mathrm{ik}}$

The coefficient can be interpreted as the change in the logodds associated with a one unit change in the corresponding independent variable or the odd increases multiplicatively by $\mathrm{e}^{\beta_{\mathrm{i}}}$ for every one unit change increase in $X_{i} i=1,2, \ldots, k$.

\subsubsection{Parameter Estimation}

In logistic regression, the parameters can be estimated by maximum likelihood estimation method. Let $\mathrm{Y}$ be the random binary response variable whose value is either zero or one and $X^{\prime}=\left(x_{1}, x_{2}, x_{3}, \cdots, x_{p}\right)$ is a vector of $\mathrm{p}$ predictor variables. The probability $P\left(Y=1 \mid x_{1}, \cdots, x_{p}\right)$ is given by:

$$
P\left(Y=1 \mid x_{1}, \cdots, x_{p}\right)=\frac{\exp \left(\alpha+\sum_{j=1}^{p} \beta_{j} x_{j}\right)}{1+\exp \left(\alpha+\sum_{j=1}^{p} \beta_{j} x_{j}\right)}
$$

The parameters of the above equation are estimated by maximum likelihood estimation technique. To apply the technique, each observation can be considered as Bernoulli trial and by assumption that each $y_{i}$ is independent, the joint distribution of the observed values can be written as: $P\left(Y_{1}=y_{1}, Y_{2}=y_{2}, \cdots, Y_{n}=y_{n}\right)=P\left(Y_{1}=y_{1}\right) P\left(Y_{2}=y_{2}\right) \cdots P\left(Y_{n}=y_{n}\right)$.

The probability of the $i^{\text {th }}$ observation given $\left(x_{1 i}, \cdots, x_{p i}\right)$ is given by

$$
P\left(Y=y_{i} \mid x_{1 i} \cdots, x_{p i}\right)=p_{i}\left(1-p_{i}\right)^{1-y_{i}},
$$

Where, $i=1, \cdots, n$ and $n$ is the number of cases in the data.

The likelihood function for

$\left(\alpha, \beta_{1}, \beta_{2}, \cdots, \beta p\right)$ given $\left(y_{1}, \cdots, y_{n}\right)$ can be expressed as

$$
L\left(\alpha, \beta_{1} \cdots, \beta_{p} \mid y_{1}, \cdots, y_{n}\right)=\prod_{i=1}^{n} p_{i}^{y_{i}}\left(1-p_{i}\right)^{1-y_{i}}
$$

By substituting $p_{i}=p\left(y=1 \mid x_{1 i}, \ldots, x p i\right)$ given above, we obtain

$$
L\left(\alpha, \beta_{1} \cdots, \beta_{p} \mid y_{1}, \cdots, y_{n}\right)=\prod_{i=1}^{n}\left\{\left[\frac{\exp \left(\alpha+\sum_{j=1}^{p} \beta_{j} x_{j i}\right)}{1+\exp \left(\alpha+\sum_{j=1}^{p} \beta_{j} x_{j i}\right)}\right]^{y_{i}}\left[\frac{1}{1+\exp \left(\alpha+\sum_{j=1}^{p} \beta_{j} x_{j i}\right)}\right]^{1-y_{j}}\right\}
$$


The log of the likelihood function is given by

$$
l=\log \prod_{i=1}^{n}\left\{\left[\frac{\exp \left(\alpha+\sum_{j=1}^{p} \beta_{j} x_{j i}\right)}{1+\exp \left(\alpha+\sum_{j=1}^{p} \beta_{j} x_{j i}\right)}\right]^{y_{i}}\left[\frac{1}{1+\exp \left(\alpha+\sum_{j=1}^{p} \beta_{j} x_{j i}\right)}\right]^{1-y_{j}}\right\}
$$

This is equivalent to

$$
l=\sum_{i=1}^{n} y_{i} \log \left[\frac{\exp \left(\alpha+\sum_{j=1}^{p} \beta_{j} x_{j i}\right)}{1+\exp \left(\alpha+\sum_{j=1}^{p} \beta_{j} x_{j i}\right)}\right]+\sum_{j=1}^{n}\left(1-y_{i}\right) \log \left(\frac{1}{1+\exp \left(\alpha+\beta_{j} x_{j i}\right)}\right)
$$

The estimates of parameters can be found by maximizing the equation using iterative techniques such as NewtonRaphson method.

\subsubsection{Assessment of Fitting Logistic Regression Model}

After fitting logistic regression model or a model has been developed through the various steps in estimating the coefficients, there are several techniques involved in assessing the appropriateness, adequacy and usefulness of the model. First, the importance of each of the explanatory variables were be assessed by carrying out statistical tests of the significance of the coefficients. Then, the overall goodness of fit of the model was tested [4].

\section{i. Model Selection}

With several explanatory variables, there are many potential models. Model selection for logistic regression faces the same issues as for ordinary regression. The selection process becomes difficult as the number of explanatory variables increases because of the increase in possible effects and interactions. In model selection, there are two competing goals: on one hand the model should be complex enough to fit the data well. On the other hand, it should be simple to interpret, smoothing rather than over fitting the data [1] Therefore, it is important to examine several possible models that allow the inclusion of many predictors and to choose a subset among them on the basis of subject matter and parsimony. Statistical software like SPSS uses either backward elimination or stepwise model selection procedures to come up with the final model. Stepwise logistic regression, the forward or backward stepwise logistic regression methods 30 utilizes the likelihood ratio test (chisquare differences) to determine automatically which variables to add or drop from the model.

\section{ii. Goodness of Fit of the Model}

The goodness of fit or calibration of a model measures how well the model describes the response variable. Assessing goodness of fit involves investigating how close values predicted by the model with that of observed values (Bewick and Jonathan, 2005). The comparison of observed to predicted values using the likelihood function is based on the statistic called deviance.

$$
\mathrm{D}=-2 \sum_{\mathrm{i}=1}^{\mathrm{n}}\left[\mathrm{y}_{\mathrm{i}} \ln \left(\frac{\widehat{\mathrm{p}}_{\mathrm{i}}}{\mathrm{y}_{\mathrm{i}}}\right)+\left(1-\mathrm{y}_{\mathrm{i}}\right) \ln \left(\frac{1-\widehat{\mathrm{p}}_{\mathrm{i}}}{1-\mathrm{y}_{\mathrm{i}}}\right)\right]
$$

For purposes of assessing the significance of an independent variable, the value of Dare compared with and without the independent variable in the equation as given below:

$\chi^{2}=\mathrm{D}$ (model without the variable) $-\mathrm{D}$ (model with the variable)

The goodness-of-fit $\chi^{2}$ process evaluates predictors that are eliminated from the full model, or predictors (and their interactions) that are added to a smaller model. In general, as predictors are added or deleted, log-likelihood decreases or increases. The question in comparing models is whether the log-likelihood decreases or increases significantly with the addition or deletion of predictor(s) in the model.

\section{Likelihood-Ratio Test}

The likelihood ratio test statistic $\left(\mathrm{G}^{2}\right)$ is the test statistic commonly used for assessing the overall fit of the logistic regression model. An alternative and widely used approach to testing the significance of a number of explanatory variables is to use the likelihood ratio test. This is appropriate for a variety of types of statistical models [4] argues that the likelihood ratio test is better, particularly if the sample size is small or the parameters are large. The likelihood-ratio test uses the ratio of the maximized value of the likelihood function for the full model $\left(\mathrm{L}_{1}\right)$ over the maximized value of the likelihood function for the simpler model $\left(\mathrm{L}_{0}\right)$. The likelihood-ratio test statistic is given:

$$
\mathrm{G}^{2}=-2 \log \left(\frac{\mathrm{L}_{0}}{\mathrm{~L}_{1}}\right)=-2\left[\log \left(\mathrm{L}_{0}\right)-\log \left(\mathrm{L}_{1}\right)=-2\left(\mathrm{~L}_{0}-\mathrm{L}_{1}\right)\right]
$$

It is compared with a $\chi^{2}$ distribution with 1 degree of freedom. This $\log$ transformation of the likelihood functions yields a chi-squared statistic.

It tests the null hypothesis that all population in logistic regression coefficient is zero except the constant one. And a small $\mathrm{p}$-value, for example, $\mathrm{p}<0.05$ leads to rejection of the null hypotheses that all of the predictor effects are zero. Thus 
when likelihood test is significant, at least one of the predictors is significantly related to the response variable.

\section{Hosmer and Lemeshow Test Statistic}

The final measure of model fit is the Hosmer and Lemeshow goodness-of-fit statistic, which measures the correspondence between the actual and predicted values of the dependent variable. The Hosmer and Lemeshow test is a commonly used test for assessing the goodness of fit of a model and allows for any number of explanatory variables, which may be continuous or categorical.

$$
\hat{C}=\sum_{k=1}^{g}\left(\left(O_{k}-O_{k}^{\prime} \bar{P}_{k}\right)^{2} /{ }_{n_{k}^{\prime}} \bar{P}_{k}\left(1-\bar{P}_{k}\right)\right)
$$

Where $\mathrm{g}$ is the number of groups, $n^{\prime}{ }_{k}$ is the number of covariate patterns in the $\mathrm{k}^{\text {th }}$ group, $O_{k}=\sum_{j=1}^{n^{\prime}{ }_{k}} y_{j}$ is the number of responses among the $n^{\prime}{ }_{k}$ covariate patterns, and $\bar{P}_{k}=m_{j} \bar{P}_{j} / n^{\prime}{ }_{k}$ is the average estimated probability.

The test is similar to a $\chi^{2}$ goodness of fit test and has the advantage of partitioning the observations into groups of approximately equal size. In this case, better model fit is indicated by a smaller difference in the observed and predicted classification [4].

The Wald Statistic: The Wald statistic is an alternative test, which is commonly used to test the significance of individual logistic regression coefficients for each independent variable (that is to test the null hypothesis in logistic regression model that a particular logit coefficient is zero).

In logistic regression we have a binary outcome variable and one or more explanatory variables. For each explanatory variable in the model there was an associated parameter.

The Wald test, described by [1] is one of a number of ways of testing whether the parameters associated with a group of explanatory variables are zero. If for a particular explanatory variable, or group of explanatory variables, the Wald test is significant, then we would conclude that the parameter associated with these variables are not zero, so that the variables should be included in the model. If the Wald test is not significant, then these explanatory variables can be omitted from the model. Wald $\chi 2$ statistic was used to test the significance of individual coefficients in the model and is calculated as:

$$
Z=\frac{\widehat{\beta}_{j}}{\operatorname{SE}\left(\beta_{j}\right)}
$$

Each Wald statistic is compared with a $\chi^{2}$ distribution with 1 degree of freedom. Wald statistic is easy to calculate but their reliability is questionable, particularly for small samples. For data that produce large estimates of the coefficient, the standard error is often inflated, resulting in a lower Wald statistic, and therefore the explanatory variable may be incorrectly assumed to be unimportant in the model (Bewick and Jonathan, 2005). The likelihood ratio test is more reliable for small sample sizes than the Wald test [1].

$\mathrm{R}^{2}$ Statistic: A number of measures have been proposed in logistic regression as an analog to $R^{2}$ in multiple linear regressions. The Cox and Snell measure is based loglikelihoods and considers sample size. The maximum value that the Cox and Snell $\mathrm{R}^{2}$ attain is less than 1 . The Nagelkerke $\mathrm{R}^{2}$ is an adjusted version of the Cox and Snell $\mathrm{R}^{2}$ and covers the full range from 0 to 1 , it is often preferred.

Therefore, in this study $\mathrm{R}^{2}$ statistic to indicate how useful the explanatory variables are in predicting the response variables were used [11].

\section{Results and Discussions}

\section{Descriptive Statistics}

Descriptive statistics utilizes numerical and graphical methods to look for patterns in a data set, to summarize the information in a data set and to present the information in a convenient form.

As indicated in Table 3 below, 77.6\% of female students have age below 22 years, $19.2 \%$ ages are between 22 and 25 years and the remaining $3.2 \%$ ages are above 25 years. It was observed that among all sampled female students, the percentage of Orthodox, Protestant, Muslim, Catholic and othersfollowers were female students' $72.8,20.8,3.2$, 2.4 and 0.8 respectively. About $37 \%$ of female students are first year students, $20 \%$ are second year students, $42 \%$ are third year students and the other $1 \%$ is above third year students. Among the total female students sampled, $90.4 \%$ of them are single, $7.2 \%$ are married and $2.4 \%$ are divorced. About $39.2 \%$ of female students are coming from rural area and the other $60.8 \%$ from urban area. About $31.2 \%, 24.8 \%, 13.6 \%$ and $30.4 \%$ female students' parents obtained less than 500 birr, between 500-1000 birr, 1001-1500 and more than 1500 birr respectively. Whereas, about $23.2 \%, 24.8 \%, 33.6 \%$ and $18.4 \%$ of student's net monthly income is below150 birr, between 150-300 birr, between 300 and 500 birr and above 500birr respectively. The result showed that $16.8 \%$ of female student's parents are illiterate, $22.4 \%$ of them have primary education, the other $24.0 \%$ of them have high school education and the rest $36.8 \%$ of them have higher education. The reslt also showed that $36.0 \%$ of female students didn't know the use of emergency contraceptive method, $23.0 \%$ of female students couldn't get the Emergency Contraceptive easily and the remaining $41.0 \%$ of female students are not allowed by their own religion to use Emergency Contraceptive Method.

Table 3. Characteristics of the practiceof ECM of Female Students (HU, 2016).

\begin{tabular}{llll}
\hline Characteristics & Count & Percent \\
\hline \multirow{2}{*}{ Age } & Less than 22 & 97 & 77.6 \\
& $22-25$ & 24 & 19.2 \\
\\
\hline
\end{tabular}




\begin{tabular}{|c|c|c|c|}
\hline Characteristics & & Count & Percent \\
\hline \multirow{5}{*}{ Religion } & Orthodox & 91 & 72.8 \\
\hline & Protestant & 26 & 20.8 \\
\hline & Muslim & 4 & 3.2 \\
\hline & Catholic & 3 & 2.4 \\
\hline & Others & 1 & 0.8 \\
\hline \multirow{5}{*}{ Batch } & one year & 46 & 36.8 \\
\hline & Two year & 25 & 20.0 \\
\hline & Three year & 53 & 42.4 \\
\hline & Above three year & 1 & 0.8 \\
\hline & Single & 113 & 90.4 \\
\hline \multirow[t]{2}{*}{ Marital status } & Married & 9 & 7.2 \\
\hline & Divorced & 3 & 2.4 \\
\hline \multirow[t]{3}{*}{ Residence } & Rural & 49 & 39.2 \\
\hline & Urban & 76 & 60.8 \\
\hline & Less than 500 & 39 & 31.2 \\
\hline Parent monthly & $500-1000$ & 31 & 24.8 \\
\hline \multirow[t]{3}{*}{ Income } & $1001-1500$ & 17 & 13.6 \\
\hline & More than 1500 & 38 & 30.4 \\
\hline & Less than 150 & 29 & 23.2 \\
\hline Net monthly & $150-300$ & 31 & 24.8 \\
\hline \multirow[t]{3}{*}{ Income } & $300-500$ & 42 & 33.6 \\
\hline & More than 500 & 23 & 18.4 \\
\hline & Illiterate & 21 & 16.8 \\
\hline Parent & Primary & 28 & 22.4 \\
\hline Education & High school & 30 & 24.0 \\
\hline \multirow[t]{2}{*}{ Level } & Higher level education & 46 & 36.8 \\
\hline & I didn't know the use & 22 & 17.8 \\
\hline Reason why not use & I couldn’t get easily & 14 & 11.2 \\
\hline \multirow[t]{2}{*}{ ECM } & Not allowed in religion & 25 & 20.0 \\
\hline & Health profession & 52 & 41.6 \\
\hline \multirow[t]{4}{*}{ Source of ECM } & Media & 33 & 26.4 \\
\hline & Teacher & 11 & 8.8 \\
\hline & Parent & 15 & 12.0 \\
\hline & Friends & 14 & 11.2 \\
\hline
\end{tabular}

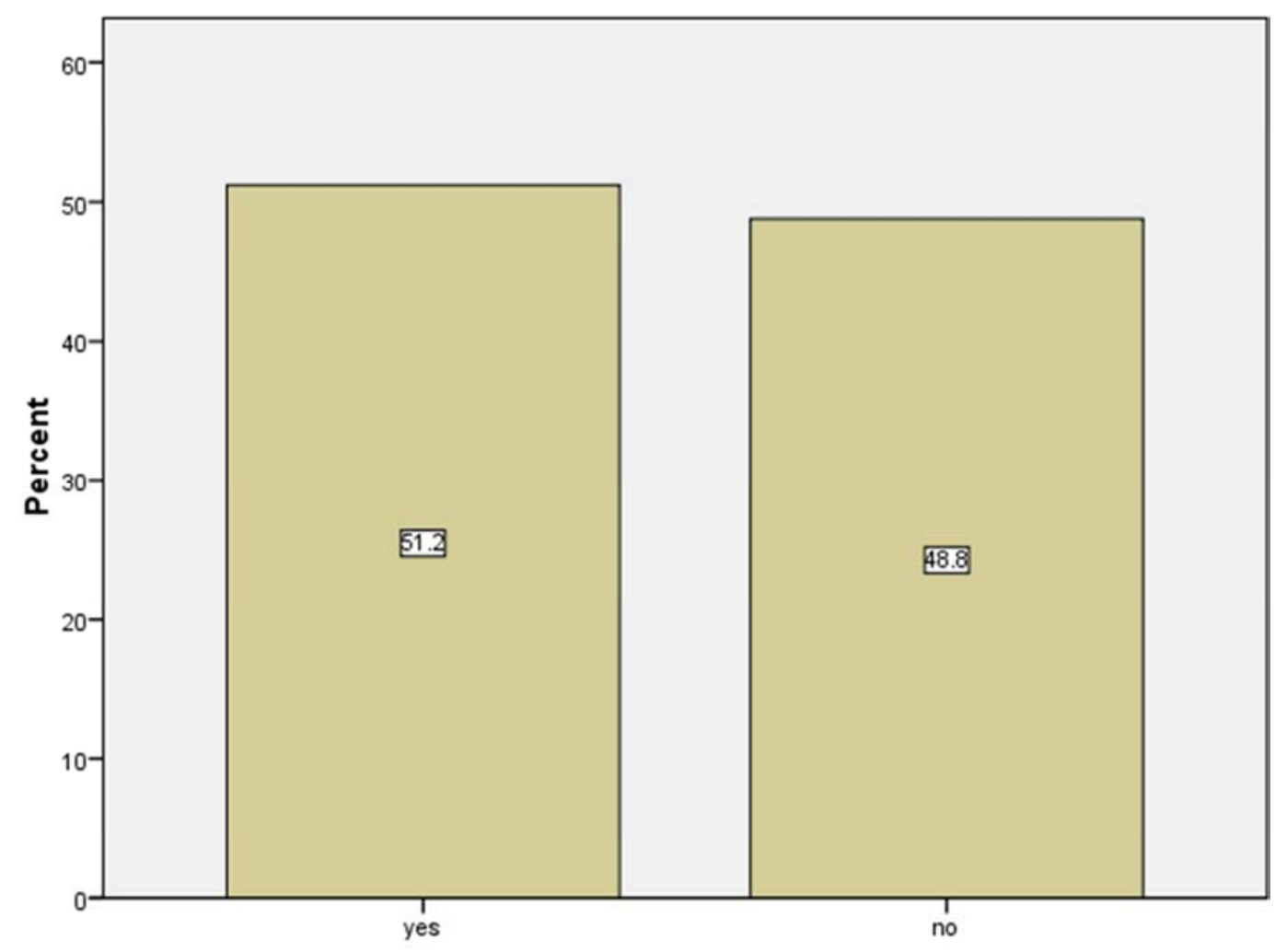

Figure 1. Bar Graph of practice of ECM. 
From the above figure, one can observe that, in Hawassa University in case of Natural and Computational Science (51.2\%) of students are using Emergency Contraceptive Method and the remaining $48.8 \%$ are not using (ECM) out of 125 sampled students.

\section{Inferential Statistics}

Chi-Square Test

A chi square test of association between usage of emergency contraceptive methods of female students and related independent variables; as Table 4 result reveals that, the chi-square test of association between usage of Emergency Contraceptive Method (ECM) of female students and batch, source and information of ECM, parental educational level as well as marital status of respondents' have the Pearson chi-square values 9.909, 9.088, 6.926 and 6.543 respectively and all the p-values are less than level of significance (0.05) and one can conclude that there is association between the usage of ECM and those independent variables.

Table 4. Chi- Square Test (HU, 2016).

\begin{tabular}{llll}
\hline Variables & Chi-square & df & p-value \\
\hline Batch & 9.909 & 3 & 0.019 \\
Residence & 1.601 & 1 & 0.206 \\
Source of ECM & 9.088 & 4 & 0.049 \\
Parent educational level & 6.926 & 3 & 0.044 \\
Marital status & 6.543 & 2 & 0.038 \\
\hline
\end{tabular}

Logistic Regression Analysis

Model Adequacy Checking

The omnibus tests are measures of how well the model performs, the chi-square tests measures the difference between the initial model and the regression model in terms of number of correctly classified subjects or it is the change in the -2log-likelihood from the previous step. Since the omnibus test issignificant, the model in final step is considered be appropriate.

Table 5. Omnibus Tests of Model Coefficients (HU, 2016).

\begin{tabular}{lllll}
\hline & & Chi-square & Df & p-value \\
\hline \multirow{2}{*}{ Final } & Step & 50.744 & 25 & .002 \\
Step & Block & 50.744 & 25 & .002 \\
& Model & 50.744 & 25 & .002 \\
\hline
\end{tabular}

Cox \& Snell R Square and Nagelkerke R- Squareare pseudo R-squares. The model summary with -2log-likelihood statistic shows the overall fit of the model as shown in Table 6. Cox and Snell R square is 0.334 , indicating that $33.4 \%$ of the variation in the variable is explained by the predictor variables and the nagelkerke R-square shows that approximately $45 \%$ of the variation in thedependent variable is explained by the predictor variables.
Table 6. Model Summary of Cox \& Snell R2 and Nagelkerke R2 (HU, 2016).

\begin{tabular}{lll}
\hline -2 Log likelihood & Cox \& Snell R Square & Nagelkerke R Square \\
\hline 114.774 & 0.334 & 0.455 \\
\hline
\end{tabular}

The Hosmer\&Lemshow statistics indicated that there is no significant difference between the observed and predicted model values and hence the model good fit tothe data as indicated in Table 7 below.

Table 7. Hosmer - Lemeshow Test (HU, 2016).

\begin{tabular}{lll}
\hline Chi-square & Df & Sig. \\
\hline 10.346 & 8 & .242 \\
\hline
\end{tabular}

From Table 8 , the positive coefficient 1.833 for $2^{\text {nd }}$ year female students indicates that batch of students and emergency contraceptive method have positive association. As the female students increases by one batch the log odds of emergency contraceptive users increased by 1.833 . The odds of usage of emergency contraceptive method of female students are6.254 times higher for second year students as compared to first year students. Whereas the positive coefficient 2.864 for third year female students show that batch of students and emergency contraceptive method have positive association. As the female students increases by one batch the log odds of emergency contraceptive users increased by 2.864 . The odds of usage of emergency contraceptive method of female students are 17.532times higher for second year students as compared to first year students.

The coefficient of marital Status tomarriedis 0.908 and its odds is 2.478. Therefore, the odds of using emergency contraceptive method 2.478 more likely than the corresponding odds for students who wasn't use emergency contraceptive method keeping the other independent variables constant.

The positive coefficient 1.407 for female students indicates that parent educational level of students and emergency contraceptive methods have positive relationship. As the female students parent education level increased the log odds of emergency contraceptive users increased by 1.407 . The odds of usage of emergency contraceptive method of female students whose parents is high school is 1.245 times higher which compared from whichilliterate parents.

The odds of female students who is getting and hearing the usage of ECM from the health professions is 30.018 times higher as compared to those getting and hearing the usage of ECM from the teachers.

Table 8. Results of the Final Multiple Logistic Regression Model(HU,2016).

\begin{tabular}{llccccc}
\hline Variables & B & S.E. & Wald & df & Sig. & Exp( $\boldsymbol{\beta})$ \\
\hline Age & & & & & & \\
Below 22 (Ref.) & -1.629 & .887 & 3.377 & 2 & .185 & \\
22-25 & 32.796 & 2.852 & 2.001 & 1 & .066 & .196 \\
Above25 & & & 1 & .079 & 1.751 \\
\hline
\end{tabular}




\begin{tabular}{|c|c|c|c|c|c|c|}
\hline Variables & B & S.E. & Wald & df & Sig. & $\operatorname{Exp}(\beta)$ \\
\hline \multicolumn{7}{|l|}{ Batch } \\
\hline $2^{\text {nd }}$ year & 1.833 & .854 & 4.613 & 1 & .032 & 6.254 \\
\hline More than $3^{\text {rd }}$ year & -39.133 & 4.497 & 1.070 & 1 & .919 & .000 \\
\hline \multicolumn{7}{|l|}{ Marital Status } \\
\hline Single(Ref.) & & & 11.799 & 2 & .003 & \\
\hline Married & .908 & .271 & 11.241 & 1 & .001 & 2.478 \\
\hline Divorced & .820 & .485 & 2.858 & 1 & .091 & 2.271 \\
\hline \multicolumn{7}{|l|}{ Residence } \\
\hline \multicolumn{7}{|l|}{ Rural(Ref) } \\
\hline Urban & -1.129 & .659 & 2.933 & 1 & .087 & .323 \\
\hline \multicolumn{7}{|l|}{ Monthly income of parents } \\
\hline lessthan 500 & & & 3.289 & 3 & .349 & \\
\hline $500-100$ & .867 & .840 & 1.065 & 1 & .302 & 2.380 \\
\hline $1001-1500$ & 1.015 & .946 & 1.151 & 1 & .283 & 2.758 \\
\hline Greater than 1500 & 1.743 & .973 & 3.208 & 1 & .073 & 5.717 \\
\hline \multicolumn{7}{|l|}{ Monthly income of Students } \\
\hline $150-300$ & -.142 & .853 & .028 & $\begin{array}{l}3 \\
1\end{array}$ & $\begin{array}{l}.164 \\
.868\end{array}$ & .868 \\
\hline $300-500$ & -.488 & .909 & .288 & 1 & .591 & .614 \\
\hline More than 500 & 2.061 & 1.369 & 2.266 & 1 & .132 & 7.855 \\
\hline \multicolumn{7}{|l|}{ Religion } \\
\hline Orthodox (Ref) & & & 3.284 & 4 & .512 & \\
\hline Muslim & -.825 & .720 & 1.313 & 1 & .252 & .438 \\
\hline Protestant & -1.482 & 1.904 & .606 & 1 & .436 & .227 \\
\hline Catholic & -2.685 & 1.813 & 2.194 & 1 & .139 & .068 \\
\hline Other & 18.863 & 4.019 & 6.02 & 1 & .86 & $1.556 \mathrm{E} 8$ \\
\hline \multicolumn{7}{|l|}{ Parent educational level } \\
\hline Illiterate (Ref) & & & 3.029 & 3 & .387 & \\
\hline Primary & .444 & .984 & .203 & 1 & .652 & 2.642 \\
\hline High School & 1.407 & .932 & 2.277 & 1 & .031 & 1.245 \\
\hline above high school & 1.658 & 1.023 & .413 & 1 & .520 & 3.518 \\
\hline \multicolumn{7}{|l|}{ Source of information about } \\
\hline EMCTeacher(Ref) & & & 7.543 & 4 & .110 & \\
\hline Parent & 1.605 & 1.047 & 2.348 & 1 & .125 & 4.977 \\
\hline Friend & .723 & .914 & .626 & 1 & .429 & 2.061 \\
\hline Constant & .538 & .757 & .506 & 1 & .477 & 1.713 \\
\hline
\end{tabular}

\section{Discussion}

The purpose of this study is to assess the usage of emergency contraceptive method of female students in Hawassa University in case of Natural and Computational Science. The study revealed that, out of the sampled students, $51.2 \%$ of them are using Emergency Contraceptive Method.

In the logistic regression analysis, the association between the emergency contraceptive usage among students and each predictor was tested. Students' family education level was found statistically significant predictor. The odds of emergency contraceptive users were higher for student whose family is high school level than un-educated. This finding was consistent with studies by [19], which revealed that the practice of contraceptive methods was more prevalent among students' family with primary education. It is possible that the higher educated women are more informed about various methods.

The frequency of following health professional advice was an important predictor on emergency contraceptive usage among students. This finding indicated that student who follow advise from professional had better chance to use emergency contraceptive methods. This result was similar with [20]. Concerning source information, students who were getting information about emergency contraceptive method from family planning field workers were less probable to practice than those who get from teachers.

Batch of students had statistically significant effect on the emergency contraceptive usage among married students. Those who were 3 rd year students are more likely to use emergency contraception methods. In addition, marital status was one of the significant predictors of emergency contraceptive usage. Students who are married were more likely to use emergency contraceptive method than students who were single.

\section{Conclusion and Recommendation}

\subsection{Conclusion}

The result obtained above can give us evidence to conclude the following.

- There is strong association between usage of emergency contraceptive method with batch of female students, marital status of female students, educational level of femalestudent and sourceinformation about emergency contraceptive method.

- The binary logistic regression results show that, batch 
of female students, marital status of female students, source of information that student gathered and student parent educational level were the major factors that affectusage of emergency contraceptive method in Hawassa University case of College of Naturaland Computational Science.

\subsection{Recommendation}

The statistical results of this study indicate that the most factors that facilitate usage of Emergency Contraceptive Method (ECM) are marital status of students' as well as source and information about Emergency Contraceptive Method (ECM). This implies, some of female students did not use Emergency Contraceptive Method. Hence, the researchers recommend that,

- Hawassa University Shouldprepare panel discussion and some brochure which deals with emergency contraceptive methods in student's clinic.

- The University should also invite some guests from the family planning bureau to teach the students when and how to use emergency contraceptive methods.

- Government and nongovernmental organizations should focus on emergency contraceptive method in the Universities.

\section{References}

[1] Agresti, A. (2002). An Introduction to Categorical Data Analysis. John Wiley and So, Inc. New York.

[2] Aziken, M. E., Okonta, P. I., \& Adedapo, B. A. (2003). Knowledge and perception of emergency contraception among female Nigerian undergraduates.

[3] Berhanu, D. and Nigatu, R. (2011) Emergency contraception among female students of Haramaya University, Ethiopia, surviving the level of knowledge and attitude.

[4] Bewick, L and Jonathan, B. (2005). Statistics Review 14: Logistic Regression.

[5] Cochran, W. G. (1977). Sampling Techniques. Third Edition, John Wiley and Sons (ASIA) Pte Ltd, Singapore. P: 428.

[6] Dkt Ethiopia, (2015) Safety of emergency contraception.

[7] Gelman, A. and Hill, J. (2007). Data Analysis using Regression and Multilevel or Hierarchical Models, Columbia
University and Columbia University

[8] Gujarati, D. (2002). basic econometrics (3rd edition). Mcgraw-hill, Inc, New York.

[9] Jones (2002) Why do university students use hormonal emergency contraception.

[10] The European Journal of Contraception and Reproductive Health Care, 8, 139-144.

[11] Jones, R. K., Dorrach, J. E., \&Henshaw, S. K. (2002). Contraceptive use among US women having abortions in2000-2001. Perspectives on Sexual and Reproductive Health, 34 (6), 294-304.

[12] Hosmer, D. and Lemeshow, S. (2000). Applied Logistic Regression ( $\left.2^{\text {nd }} E d.\right)$, New York.

[13] Kongnyuy, E. (2007) A survey of knowledge, attitude and practice of emergency contraception among university students in Cameroon, BMC Emergency medicine.

[14] Kwikmed, B. (2014) The emergency contraceptive pill: a survey of knowledge and attitudes among students at Princeton University.

[15] Mathew's, W. (1991). Family planning survey among Ethiopian Domestic Corporation Employees. Eth. J Health Dvt. 7(2): 86-91.

[16] Ramash, A. (2009) factor affecting awareness of emergency contraception among college students in Kathmandu, Nepal.

[17] Victor, M. (2014) Adiposity hypertension and weight management behaviors in Ghanaian type 2 diabetes mellitus patients age $20-70$ years.

[18] WHO. (1999) Expanding options in reproductive health: An assessment of reproductive health needs.

[19] Islam, M. and Muhmud, M. (1995). Contraceptionamong adolescents in Bangladesh Asian-pacific population Journal. United Nation: 10 (1): 21-38.

[20] Kabir, M. and Islam, A. (2000). The Impact of Mass Media Family Planning Programmes on Current Use of Contraception in Urban Bangladesh.

[21] Patriciao and Eskaya, S. (2005). Contraceptive use and method choice in Turkey. International journal of Gynecology and Obstetrics. 75 (1): 87-98.

[22] Central Statistical Agency (CSA), (2006). Summary and Statistical Report of Population and Housing Census Results. 2006. Addis Ababa, Ethiopia. 